\title{
Síndrome de Behçet: à Procura de Evidências
}

\section{Behçet's Syndrome: Looking for Evidences}

\author{
Fabrício de Souza Neves ${ }^{(1)}$, Júlio César Bertacini de Moraes $^{(1)}$, Célio Roberto Gonçalves ${ }^{(2)}$
}

\begin{abstract}
RESUMO
A síndrome de Behçet (SB) é uma afecção inflamatória multissistêmica, de acometimento vascular e de causa ainda desconhecida, basicamente caracterizada por úlceras orais e genitais recorrentes, uveíte e lesões cutâneas. A perda da visão é freqüente, resultado de ataques repetidos de inflamação. Reconhecida atualmente como um modelo singular de vasculite, a SB parece apresentar elementos de suscetibilidade genética do portador e fatores ambientais desencadeantes. O estabelecimento de critérios internacionais de diagnóstico/classificação, em 1990, e protocolos clínicos em desenvolvimento para medida da atividade da doença podem permitir a padronização das pesquisas na área. Neste artigo são revistos dados epidemiológicos, clínicos, as hipóteses correntes sobre etiogenia e fisiopatologia e dados atuais sobre as diferentes intervenções terapêuticas, considerando as drogas imunossupressoras clássicas e os novos agentes biológicos, destacando a necessidade de novas informações baseadas em evidências nesta área.
\end{abstract}

Palavras-chave: síndrome de Behçet, literatura de revisão, medicina baseada em evidências, vasculite.

\section{INTRODUÇÃO}

A síndrome de Behçet (SB) é uma afecção inflamatória multissistêmica, de acometimento vascular e causa ainda desconhecida, basicamente caracterizada por úlceras orais recorrentes, úlceras genitais, uveíte e lesões cutâneas, além de múltiplas outras manifestações sistêmicas menos comuns. Não se trata de doença com atividade inflamatória crônica e persistente, sendo mais comum a apresentação de ataques recorrentes de inflamação aguda. Embora a maior parte de suas manifestações seja considerada benigna e autolimitada, ataques repetidos de inflamação ocular podem levar à cegueira, principal morbidade seqüelar da síndrome. O acometimento do sistema nervoso central (SNC)

\begin{abstract}
Behçet's syndrome (BS) is an inflammatory disorder, currently known as a singular model of vasculitis, characterized by recurrent oral and genital ulcers, uveitis and skin lesions. Blindness is frequent, resulting from repeated attacks of uveitis. Genetic susceptibility and environmental factors can be associated with this syndrome. International diagnostic criteria, established in 1990, and the development of disease activity measurement criteria may allow worldwide standardization of clinical trials. This article reviews epidemiological and clinical data, the current hypothesis about causation and pathophysiology and presents a discussion about therapeutic interventions. It includes classic immunossupressive drugs and new biologic agents, and points the need for new evidenced based information about BS treatment.
\end{abstract}

Keywords: Behcet's syndrome, review literature, evidenced based medicine, vasculitis.

e de grandes vasos, manifestação menos comuns, pode ser agudamente grave ou progressivo, com importante letalidade ${ }^{(1,2)}$. Rara em grande parte do mundo, a SB concentra-se em distribuição geográfica peculiar, coincidindo com a antiga "Rota da Seda", de Marco Pólo - faixa que se estende da bacia do Mediterrâneo ao extremo Oriente. A Turquia apresenta as maiores prevalências, alcançando até 370 casos por 100 mil habitantes ${ }^{(3)}$, e foi a origem dos casos descritos em 1937, pelo dermatologista turco Hulusi Behçet, que reconheceu o caráter sistêmico da síndrome. Atualmente, considerada um modelo singular de vasculite, a SB parece apresentar, implicados em sua origem, elementos de suscetibilidade genética (dentre os quais se destaca

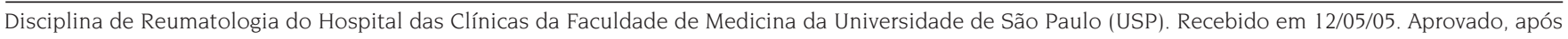
revisão, em 12/09/05.

1. Médico Residente da Disciplina de Reumatologia do Hospital das Clínicas da Faculdade de Medicina da USP.

2. Médico Assistente da Disciplina de Reumatologia do Hospital das Clínicas da Faculdade de Medicina da USP.

Endereço para correspondência: Fabrício de Souza Neves, Rua Dr. Diogo de Faria 1104, ap 92, Vila Clementino, São Paulo, CEP 04037-003, SP, Brasil,

e-mail: nevesfab@bol.com.br 
a associação com o HLA-B5l) em interação com fatores ambientais desencadeantes $^{(4)}$. Com o estabelecimento de critérios internacionais de diagnóstico/classificação, em $1990^{(5)}$, e o posterior desenvolvimento de protocolos clínicos para medida de sua atividade ${ }^{(6)}$, instrumentos necessários à padronização de pesquisas, a síndrome tem despertado maior interesse nos últimos anos. No entanto, o tratamento da SB compreende diversas estratégias ainda indicadas de forma empírica, devido à presente escassez de informação baseada em evidências na área.

\section{EPIDEMIOLOGIA}

Embora relatos da SB ocorram mundialmente, sua prevalência é marcadamente mais alta em países situados na "Rota da Seda". Um levantamento realizado em área rural da Anatólia, nordeste da Turquia, encontrou a prevalência de 370 casos por 100 mil habitantes, valor máximo registrado pela literatura. Na capital turca, Ankara, este valor foi determinado em 110 por 100 mil habitantes maiores de 10 anos de idade ${ }^{(3)}$. As prevalências da SB são bem inferiores em países ocidentais $(0,64$ e 0,33 por 100 mil na Inglaterra e nos Estados Unidos, respectivamente), tendo valores intermediários nos demais países da "Rota da Seda": no Irã, na Arábia Saudita e na Coréia do Sul, ela varia entre 13 a 20 casos por 100 mil habitantes. Fora da Turquia a maior prevalência foi encontrada na região de Hokkaido, no Japão, onde há 30,5 casos por 100 mil pessoas. Valores intermediários de prevalência também foram encontrados em população de origem turca vivendo em Berlim (21 casos por 100 mil habitantes, proporção inferior à descrita na Turquia, mas bem superior à prevalência entre os habitantes de Berlim com origem germânica, estimada em 0,42 por 100 mil pessoas) $)^{(1,3)}$.

Trata-se de uma doença de adultos jovens, com idade média de início entre 25 e 30 anos. Porém, casos já foram relatados iniciando na oitava década de vida, bem como em neonatos. Inicialmente, o sexo masculino era o mais acometido pela síndrome na Turquia e em Israel. Atualmente, a maioria dos estudos epidemiológicos aponta para proporções semelhantes entre os sexos, inclusive nestes dois países. Descrição de ocorrência familiar ocorre em até $18 \%$ dos casos, na Turquia, sendo bem mais rara nos demais países.

Os dados epidemiológicos da síndrome (em particular, sua distribuição geográfica peculiar, as prevalências variáveis, conforme grupos étnicos e correntes migratórias, e a proporção variável entre sexos ao longo do tempo) acabaram sugerindo aos investigadores que uma possível associação entre fatores genéticos predisponentes e elementos ambientais desencadeantes seria responsável pelo desenvolvimento da SB em uma determinada população.

\section{PATOGÊNESE}

Desde a primeira descrição da associação entre a SB e o alelo HLA-B51 (Human Leucocyte Antigen - Antígeno Leucocitário Humano) do MHC (Major Histocompatibility Complex - Complexo Principal de Histocompatibilidade) classe I, feita por Ohno, em $1982^{(7)}$, diversos estudos encontraram relação entre a síndrome e o alelo nos países da "Rota da Seda", mas geralmente não nos países ocidentais. No Japão, a freqüência do HLA-B5l é mais alta em doentes de Behçet do que na população geral $(55 \%$ contra 10 a $15 \%$ ), e o risco relativo para a doença entre portadores do HLA-B51 é de 6,7 (contra apenas 1,3 nos EUA). A presença do HLA-B51 também está associada à expressão mais completa das manifestações da síndrome e com um curso clínico mais grave ${ }^{(1,8)}$.

Uma relação direta entre o alelo HLA e o desenvolvimento da síndrome não foi experimentalmente comprovada. Embora os neutrófilos do sangue periférico de camundongos transgênicos com HLA-B5I demonstrem um estado de hiper-reatividade ${ }^{(9)}$, não se conseguiu demonstrar nestes animais respostas proliferativas de linfócitos ou produção aumentada de citocinas, nem alguma manifestação clínica compatível com a síndrome, face a estímulos com peptídeos considerados desencadeantes da SB em outros modelos experimentais ${ }^{(4)}$. Produtos de outros genes, provavelmente transmitidos em desequilíbrio de ligação com o HLA-B51, podem estar mais diretamente envolvidos na patogênese da SB. Neste campo de pesquisa, destaque foi obtido pelos alelos do grupo do "gene A relacionado ao MHC classe I" (MICA - MHC class I related gene A). Na Coréia do Sul, Park et a ${ }^{(10)}$ descreveram freqüências elevadas tanto do HLA B-5l quanto do alelo MICA*A6 nos pacientes com SB e suas famílias em relação aos controles saudáveis, estando este alelo também associado à ocorrência da síndrome em pacientes HLA-B51 negativos. Wallace et $a^{(11)}$, na Inglaterra, descreveram relações semelhantes também para o alelo MICA*009.

Os genes do grupo MICA são transcritos por células humanas em resposta a situações de hipertermia, anoxia ou metabólitos tóxicos, gerando produtos que pertencem ao grupo das "proteínas de choque térmico" (HSP - heat shock proteins), e sugerem que sejam capazes de atuar como moléculas apresentadoras de antígenos a linfócitos $\mathrm{T}$. 
Já se descreveu que alguns peptídeos derivados da HSP 65 $\mathrm{kD}$ microbiana são capazes de estimular especificamente linfócitos $\mathrm{T} \gamma \delta+$ de pacientes com SB. Estes peptídeos específicos guardam homologia com a HSP $60 \mathrm{kD}$ humana que é expressa em quantidade aumentada nas células epiteliais das lesões cutâneas de pacientes com SB. Informações como estas permitiram a Lehner ${ }^{(4)}$ apresentar, em 1999, um modelo imunopatogenético, no qual reação imune cruzada a antígenos compartilhados por agentes microbianos, e proteínas expressas por pacientes geneticamente suscetíveis em situações de estresse infeccioso, seriam responsáveis pelas lesões teciduais na $\mathrm{SB}^{(4)}$.

Modelos experimentais para indução de uveítes foram obtidos com cobaias, inclusive com a administração por via oral a ratos Lewis do peptídeo p336-351 derivado da HSP $65 \mathrm{kD}^{(12)}$. Teoricamente, essa situação no paciente humano, cuja mucosa oral ou o trato digestivo exposto a um antígeno microbiano, ainda desconhecido, capaz de provocar direta ou indiretamente as ulcerações orais características da síndrome, poderia ser reconhecida por linfócitos $\mathrm{T}$ específicos e desencadear, no indivíduo predisposto, a resposta imune responsável pelas diversas manifestações da síndrome ${ }^{(4,13)}$.

Vários agentes microbianos já ocuparam a posição de suspeitos desencadeadores deste processo. Algumas espécies de estreptococos encontradas na flora oral já foram sugeridas como causadoras de lesões aftosas recorrentes. Sorotipos incomuns de Streptococcus sanguis e anticorpos contra esta bactéria foram encontrados em flora oral e no sangue, respectivamente, de pacientes com SB. A expressão da HSP $65 \mathrm{kD}$ por esta bactéria, demonstrada por Lehner ${ }^{(4)}$, tenta completar seu modelo de patogênese. Porém, anticorpos contra o vírus herpes simples e o próprio DNA viral também foram encontrados em proporção mais alta em pacientes com SB que em controles saudáveis ${ }^{(1)}$. Anticorpos contra Saccharomyces cerevisiae, levedura utilizada como fermento na fabricação de alimentos, foram encontrados em $48,1 \%$ dos portadores de SB contra $10,1 \%$ dos controles no estudo israelense de Krause et $a^{(14)}$, tornando mais remota a idéia de que um único agente (ou um único grupo específico de micróbios) possa ser responsável pela origem da síndrome. Ao contrário, o conjunto de tais estudos aponta para um estado de hiper-reatividade a antígenos comuns no meio ambiente ${ }^{(1,2)}$.

\section{FISIOPATOLOGIA}

O quadro patológico da SB consiste em vasculite, encontrada em biópsias em torno das lesões mucocutâneas, bem como em vasa vasorum dos grandes vasos acometidos pela síndrome, superimposta a um estado de hipercoagulabilidade também característico da SB, com formação de trombos venosos ou arteriais $^{(15)}$. As lesões ativas são infiltradas por neutrófilos, considerados hiper-reativos na $\mathrm{SB}$, com quimiotaxia exacerbada e produção aumentada de diversas enzimas lisossômicas ${ }^{(1)}$. Linfócitos T e B também são encontrados no infiltrado perivascular. Existem evidências de que os linfócitos $T \gamma \delta+$ estejam presentes em maior número e com maior capacidade funcional nos pacientes com $\mathrm{SB}^{(16)}$. Citocinas promotoras de atividade $\mathrm{T}$ helper 1 (IFN- $\gamma$, IL-2 e IL-12) são mais comumente encontradas em níveis elevados (IL - interleucina; IFN - interferon). Células Natural Killer (NK), embora também em maior número, apresentam citotoxicidade diminuída ${ }^{(17)}$, sugerindo um direcionamento para a resposta imune do tipo celular, que atuaria de forma inadequada nestes pacientes. A produção aumentada das citocinas pró-inflamatórias IL-1 e TNF (Fator de Necrose Tumoral) pode estar relacionada aos mecanismos de lesão tecidual ${ }^{(4)}$, inclusive com polimorfismos específicos do TNF e da molécula de adesão intercelular 1 (ICAM-1) identificados em pacientes com $\mathrm{SB}^{(18)}$.

As razões subjacentes às anormalidades de coagulação observadas na SB são pouco conhecidas. Pesquisando as causas mais freqüentes de trombofilia, Espinosa et a ${ }^{\left({ }^{(19)}\right.}$ não encontraram relação da SB com a mutação do fator $\mathrm{V}$ de Leiden, deficiências de proteínas $\mathrm{C}, \mathrm{S}$ ou de antitrombina III ou ainda com a mutação do gene da protrombina. A relação com hiperhomocisteinemia é controversa e, embora sejam descritos níveis mais elevados de homocisteína em doentes com SB, Korkmaz ${ }^{(20)}$ demonstrou não haver diferença significante nestes níveis entre os pacientes com e sem ocorrência de tromboses.

Até o momento, auto-anticorpos não são considerados parte do espectro da SB. Ao contrário de outras condições auto-imunes de acometimento vascular ou hematológicos, anticorpos anticardiolipina e anticitoplasma de neutrófilos não estão associados à $\mathrm{SB}^{(2)}$. Lee et $\mathrm{a}^{(21)}$ recentemente demonstraram que anticorpos $\operatorname{Ig} M$ contra a alfa-enolase (um tipo específico de auto-anticorpo contra células endoteliais) estavam presentes em 18 de 40 pacientes com SB (45\%), porém dados atestando a especificidade deste achado também não foram conclusivos. Embora lesão direta das células endoteliais não tenha sido observada, a disfunção destas células na forma de um desequilíbrio entre fatores trombogênicos/vasoconstritores contra antitrombóticos/vasodilatadores pode ser suposta e já 
foram descritos níveis elevados de endotelina e reduzidos de prostaciclina em $\mathrm{SB}^{(4)}$.

De forma simplificada (apresentada na Figura 1), o conhecimento atual sugere que o processo fisiopatológico se inicia com a exposição a antígenos infecciosos. Estes, ao serem processados pelas células apresentadoras de um indivíduo com uma predisposição geneticamente determinada (associada ao HLA-B51, ou diretamente expressa através do grupo MICA), são capazes de desencadear resposta imune inadequadamente direcionada para a forma "celular" (envolvendo um número excessivo de células $\mathrm{T} \gamma \delta+\mathrm{e}$ linfócitos $\mathrm{T}$ helper 1 "citótoxicos"). Este processo culmina em neutrófilos hiper-reativos que são responsáveis pela lesão tecidual, afetando células do paciente que expressam moléculas semelhantes às do agente infeccioso inicial. A conseqüente disfunção de células endoteliais atuaria como principal deflagradora de eventos trombóticos na circulação sanguínea.

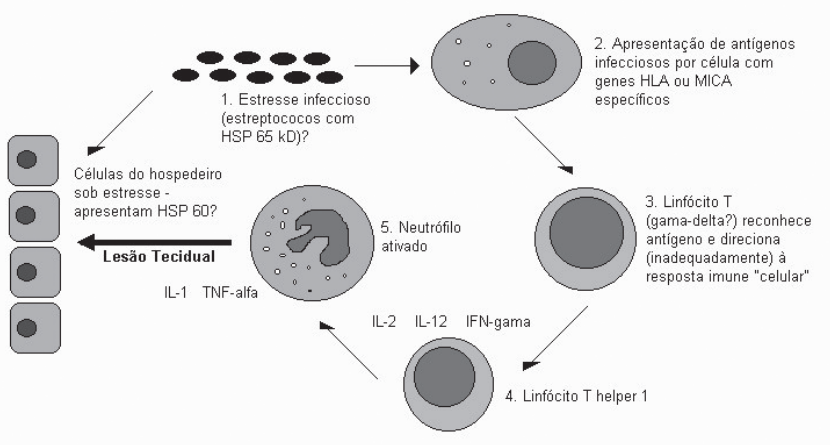

Figura 1 - Modelo fisiopatológico da síndrome de Behçet: antígenos infecciosos (1), provavelmente diversos, mas com destaque para antígenos estreptocócicos, são processados por células apresentadoras (2) de indivíduos geneticamente predispostos, caracterizados por alelos HLA ou MICA específicos, desencadeando resposta imune inadequadamente direcionada para a forma "celular", através da participação de linfócitos T gama-delta (3), predomínio de citocinas específicas (IL2, IL-12 e IFN-gama) e linfócitos T helper-1 (4) com hiperativação de neutrófilos (5), responsáveis pelas lesões teciduais em células que expressam moléculas semelhantes aos antígenos desencadeadores do processo (6).

\section{QUADRO CLIINICO E DIAGNÓSTICO}

As primeiras descrições de achados clínicos compatíveis com a SB são encontradas nos registros de Hipócrates, do século V a.C: “(...) muitos desenvolveram ulcerações aftosas. Muitas ulcerações sobre os genitais (...) oftalmias lacrimosas de caráter crônico, com dores; excreções fúngicas das pálpebras externamente, e internamente, que destruíram a vista de muitas pessoas (...)". No início do século passado acumularam-se relatos de casos envolvendo a ocorrência de lesões recidivantes orais, genitais e oculares, culminando com o reconhecimento formal da síndrome no Congresso Internacional de Dermatologia de 1947 com o nome do dermatologista turco Hulusi Behçet, que descrevera a tríade de ulcerações orais, genitais e inflamação ocular como uma entidade única em $1937^{(22)}$. Posteriormente, muitas outras manifestações associadas à SB foram sendo reconhecidas, configurando seu caráter multissistêmico.

Úlceras aftosas orais representam a manifestação inicial da SB em $47 \%$ a $86 \%$ dos casos, usualmente precedendo em alguns anos as demais manifestações da síndrome ${ }^{(3)}$. As lesões típicas são dolorosas, menores que $10 \mathrm{~mm}$ e curam sem cicatrizes em cerca de dez dias. As úlceras genitais têm aspecto semelhante, porém são maiores e costumam deixar cicatriz, que muitas vezes auxilia no diagnóstico. Dentre as manifestações cutâneas, eritema nodoso e pseudofoliculite /nódulos acneiformes são aproximadamente equivalentes em freqüência. O primeiro é mais comum nas mulheres, é doloroso e geralmente cura deixando área hiperpigmentada, normalmente na face anterior das pernas. A segunda ocorre principalmente em homens, na face, pescoço e dorso, podendo estar associada a traumatismos, como o ato de barbear-se, devido à hiper-reatividade cutânea que é a base do teste da patergia ${ }^{(1)}$. A inserção oblíqua de uma agulha de calibre 20 Gauge na pele em condições estéreis, sem injeção de salina, deve produzir um nódulo eritematoso ou pustular no local após 24 a 48 horas para se considerar resultado positivo ${ }^{(23)}$. Tromboflebites superficiais também fazem parte do espectro de manifestações cutâneas. O acometimento ocular mais característico, uveíte anterior (iridociclite) ou posterior (corioretinite) em surtos repetidos podem levar à deformidade da íris e comprometer a visão, mas lesões oclusivas de vasos retinianos mais freqüentemente conduzem à cegueira na $\mathrm{SB}$ e, ao contrário dos episódios de uveíte anterior, são indolores e evoluem de forma silenciosa. Manifestações articulares correspondem a artralgias ou artrites de grandes articulações, notadamente em membros inferiores sendo raramente destrutivas ${ }^{(1)}$.

No trato gastrintestinal, o acometimento ocorre com formação de úlceras (semelhantes às descritas na cavidade oral) ao longo do tubo digestivo e que podem se manifestar como dor abdominal, diarréia, hemorragia digestiva ou perfuração ${ }^{(23)}$. Trata-se da manifestação mais comum no extremo Oriente (onde foram descritas úlceras únicas e grandes em colonoscopias), do que na Turquia, onde poucos casos são descritos (sendo observadas úlceras pequenas e múltiplas em íleo terminal) ${ }^{(2)}$. No sistema nervoso central (SNC) qualquer estrutura pode ser afetada. Uma forma de meningite asséptica pode ocorrer na fase inicial da SB, de curso benigno. Tromboses dos seios venosos cerebrais levando à cefaléia, paralisia de nervos cranianos e alterações 
mentais são uma forma característica de acometimento neurológico na SB, conhecida como "extra-axial", que se acredita estar associada a outras formas de acometimento de grandes vasos. A forma dita "intra-axial" ou parenquimatosa consiste em défcits neurológicos localizados, mais comuns no tronco cerebral, mas também podendo ser hemisféricos ou cerebelares, atribuídos à vasculite de pequenos vasos, de predominância venosa. Sintomas neuropsiquiátricos podem se desenvolver sem relação a anormalidades estruturais detectáveis à Ressonância Magnética (RM). Cefaléia primária (não-estrutural) também é um sintoma neurológico comum na $\mathrm{SB}^{(24)}$. O envolvimento de grandes vasos também ocorre em conseqüência de vasculite de vasa vasorum, culminando em oclusão (venosa ou arterial) ou na formação de aneurismas. Tais eventos podem ser fatais, particularmente aqueles que ocorrem na árvore arterial pulmonar, com hemorragia alveolar, hemoptise ou oclusão arterial pulmonar ${ }^{(1)}$. Envolvimento pleural é muito raro, assim como pericardite ou outras manifestações cardíacas (lesões valvares ou de coronárias). No trato genitourinário, orquiepididimite é a manifestação mais freqüentemente descrita, embora glomerulonefrite também possa ocorrer ${ }^{(2,23)}$.

Em tentativas de sistematizar a abordagem diagnóstica, tais manifestações foram classificadas em "maiores" e "menores", conforme a freqüência de suas ocorrências. Segundo Barnes e Yazici(23), em revisão de 1999, são consideradas manifestações maiores: ulceração oral recorrente $(97 \%$ a $98 \%$ dos casos); ulceração genital ( $80 \%$ a $90 \%)$; lesões cutâneas ( $80 \%$ ) e doença inflamatória ocular (50\%). Manifestações menores compreendem: artralgias ou artrites ( $45 \%$ a $50 \%)$; lesões neurológicas ( $5 \%$ a $25 \%$ ); lesões vasculares $(25 \%)$; lesões gastrintestinais (0 a $25 \%)$; epididimite $(8 \%)$; lesões cardíacas e pleuropulmonares. Anteriormente, outros autores já haviam apresentado painéis de manifestações maiores e menores com ligeiras diferenças, incluindo ou excluindo associações menos freqüentes como comprometimento renal, amenorréia ou história familiar. Diversas orientações foram publicadas quanto aos critérios necessários para o diagnóstico da SB, existindo pelo menos cinco conjuntos de critérios em uso até a década de 90 . Uma tentativa de uniformização foi apresentada em 1990 pelo International Study Group for Behçet's Disease (ISGBD) através da elaboração de um novo conjunto mais conciso de critérios diagnósticos para a SB (Tabela 1), no qual ulcerações orais recorrentes (três vezes no período de doze meses) devem obrigatoriamente estar presentes, associadas a quaisquer dois dos demais quatro critérios: ulceração genital recorrente; lesões ocu- lares (uveíte anterior ou posterior, células no vítreo ou vasculite retiniana observados por oftalmologista); lesões cutâneas (não recebendo corticosteróides) e teste positivo de patergia ${ }^{(5)}$. Embora tais parâmetros tenham sido inicialmente publicados sob o título de critérios diagnósticos, os próprios autores enfatizaram que sua principal utilidade é assegurar a uniformidade de pacientes incluídos em estudos, permitindo a comparação entre grupos, não devendo representar a única ferramenta para diagnóstico de casos individuais. A denominação "critérios de classificação" é preferível, a exemplo do que ocorre em painéis elaborados para outras entidades reumatológicas ${ }^{(23,25)}$.

TABELA 1

Critérios de Classificação da síndrome de BehÇEt (SB)

1. Ulcerações orais recorrentes (pelo menos três vezes no período de 12 meses)

2. Ulceração genital recorrente

3. Lesões oculares (uveíte anterior, uveíte posterior, células no vítreo ou vasculite retiniana)

4. Lesões cutâneas (eritema nodoso, pseudofoliculite, lesões papulopustulares ou acneiformes)

5. Teste de patergia positivo

Um paciente pode ser classificado como portador da síndrome de Behçet quando o critério 1 está presente, associado a quaisquer dois dos demais critérios, não necessariamente de forma simultânea.

Fonte: International Study Group for Behçet's Disease, 1990(5).

A apresentação clínica da SB não é uniforme. Diferentes manifestações são relatadas em populações diversas, surgindo classificações conforme sua forma de acometimento preferencial. Já se descreveu também a ocorrência da associação freqüente de artrites com lesões papulopustulares na SB sugerindo-se que, neste grupo de pacientes, possa existir um processo fisiopatológico comum às duas lesões (talvez desencadeado por um agente específico, possivelmente estreptococos) $)^{(26)}$. Considerando que poderiam existir diferenças nos mecanismos imunopatogênicos entre os diferentes padrões da SB, termos como neuroBehçet, vásculo-Behçet ou entero-Behçet são algumas vezes empregados para caracterizar pacientes com uma forma preferencial de acometimento ${ }^{(25)}$. Existem também diferenças geográficas quanto à prevalência destas formas: a freqüência de acometimento intestinal é menor nos países mediterrâneos do que no extremo Oriente, bem como a forma ocular é mais comum no sul da Europa (Itália e 
Grécia) em comparação aos países do norte europeu ${ }^{(2,3)}$. Tais diferenças na forma de apresentação e a inexistência de agente etiológico ou mecanismo etiopatogênico único e bem definido fazem com que muitos autores enfatizem que a denominação "síndrome de Behçet" seja preferível à "doença de Behçet"(23).

O curso clínico da SB é caracterizado por períodos sucessivos de atividade e remissão. As exacerbações são classicamente descritas como mais freqüentes e graves em pacientes masculinos e com idade de início da doença mais precoce. A maioria dos pacientes alcança remissão ou estabilidade clínica com quadro seqüelar após cerca de quatro a cinco anos de evolução, exceto nos casos de comprometimento vascular ou neurológico que podem ter início tardiamente no curso da doença (após cinco a dez anos de evolução). Também são estas as manifestações de pior prognóstico: a mortalidade pode alcançar $20 \% \mathrm{em}$ sete anos nos pacientes com lesão neurológica e $50 \%$ em três anos nos pacientes com hemoptise por lesões de vasos pulmonares $^{(1,27)}$.

Embora as idéias de atividade e remissão estejam presentes em todas as descrições e trabalhos sobre SB, seus conceitos nunca foram claramente definidos, sendo diferentes em várias publicações e, algumas vezes, significando impressão subjetiva por parte do clínico. Nenhum marcador laboratorial revelara também correlação definida com a impressão clínica de atividade em $\mathrm{SB}^{(1,2)}$. Neste contexto, após a apresentação dos critérios de diagnóstico/classificação do ISGBD em 1990, surgiram esforços para instituir um instrumento padronizado, reproduzível internacionalmente, para medida da atividade da doença ${ }^{(6)}$. Um protocolo, denominado Behçet's Disease Current Activity Form (BDCAF), foi elaborado em 1994 por um comitê internacional, combinando características de dois protocolos existentes (um europeu e um iraniano). Desde então, vem sendo aplicado como modelo em estudos de avaliação como instrumento de medida da atividade da doença $^{(6,28)}$. Em 2004, Lawton et a ${ }^{(29)}$ avaliaram a aplicabilidade dos diversos itens deste protocolo na tentativa de calcular um índice numérico unidimensional para a medida da atividade da SB, denominado Behçet's Disease Activity Index (BDAI). Consideraram válidos 14 itens, tratados como variáveis dicotômicas. Neste protocolo, apenas dados clínicos, obtidos diretamente da entrevista com o paciente, são considerados marcadores da atividade da SB (Tabela 2).

Não são descritas, até o momento, provas laboratoriais que se relacionem de forma confiável com todas as possí- veis formas de manifestação. Na apresentação do BDCAF considerou-se que a inclusão da dosagem da proteína $\mathrm{C}$ reativa (PCR) e da velocidade de hemossedimentação (VHS) não acrescentaria valor à medida da atividade baseada em dados clínicos, porém os autores recomendaram que valores alterados nestes exames devem abrir margem à investigação adicional, em caso de doença aparentemente inativa $^{(6)}$. Na Turquia, Aygunduz et al ${ }^{(30)}$ encontraram VHS e PCR mais elevados que controles saudáveis, tanto em pacientes com SB considerada ativa ou em remissão. Porém, mais especificamente, outros autores já relacionaram PCR e VHS elevadas à presença de eritema nodoso, artrite e tromboflebite ativas em doentes de Behçet, mas não à atividade ocular, úlceras orais, em SNC ou gastrintestinal ${ }^{(31)}$. Sugeriu-se que a determinação da beta- 2 microglobulina poderia servir como medida mais fidedigna da diferença entre atividade e remissão na $\mathrm{SB}^{(30)}$. Odabas et $a^{(32)}$ encontraram níveis de ferritina significativamente elevados nos pacientes com doença considerada ativa em relação aos controles com doença inativa. E embora algumas observações a respeito da positividade da patergia em casos considerados ativos da SB já tenham sido relatadas, estudos com este teste são poucos e inconclusivos ${ }^{(33)}$. Faltam também dados relacionando os diversos marcadores laboratoriais à atividade em sistemas orgânicos específicos, nas diferentes manifestações da síndrome.

TABELA 2

CRITÉrios ClínICOS PARA AVALIAÇ̃̃o DA ATIVIDADE DA SÍNDROME DE BEHÇET (SB)

\begin{tabular}{l} 
1. Úlceras orais \\
2. Úlceras genitais \\
3. Eritema nodoso \\
4. Pústulas \\
5. Artralgia \\
6. Artrite \\
7. Náuseas ou vômitos \\
8. Diarréia \\
9. Cefaléia \\
10. Sinais ou sintomas de atividade ocular \\
11. Sinais ou sintomas de atividade em sistema nervoso central \\
12. Sinais ou sintomas de atividade em grandes vasos \\
13. Auto-avaliação do paciente (sobre escala semi-quantitativa) \\
14. Impressão geral do clínico (sobre escala semi-quantitativa) \\
\hline a presença dos critérios acima nas quatro semanas anteriores é utilizada para quantificar \\
centros ainda não foram convenientemente avaliadas. Fonte: Lawton, 2004 (45)
\end{tabular}




\section{TRATAMENTO}

Intervenções terapêuticas são variadas e, muitas vezes, exigem interdisciplinaridade entre especialistas. Existem poucas evidências fundamentadas quanto à eficácia das drogas tradicionalmente indicadas, de forma ainda empírica, no tratamento das diferentes manifestações da SB. Uma revisão Cochrane recentemente publicada conseguiu incluir apenas dez ensaios clínicos randomizados e controlados, podendo confirmar eficácia apenas da azatioprina e da ciclosporina para proteção ocular e da penicilina benzatina na profilaxia dos episódios de artrite. Porém, foram considerados apenas trabalhos publicados até janeiro de $1998^{(34)}$.

Úlceras genitais e orais são em geral adequadamente tratadas com corticosteróides tópicos. Nos períodos de exacerbação das lesões mucocutâneas, corticosteróides sistêmicos podem ser empregados ${ }^{(1)}$. Colchicina, talidomida e dapsona podem ser usados na prevenção das recidivas (os três avaliados em ensaios clínicos controlados), embora apresentando resultados apenas modestos. Colchicina reduziu a frequiência de artrites, úlceras genitais e eritema nodoso em mulheres, mas apenas de artrites em homens, em estudo com 116 casos $^{(35)}$. Talidomida manteve a ausência completa de lesões orogenitais em 16\% dos pacientes tratados durante o seguimento de dois anos, reduzindo também a freqüência das lesões papulopustulares, num estudo com pacientes do sexo masculino ${ }^{(36)}$. Dapsona demonstrou resposta positiva no controle de lesões mucocutâneas apenas num pequeno ensaio com 20 pacientes $^{(37)}$.

Colírios de corticosteróides e agentes midriáticos são eficazes nas uveítes anteriores, mas a via sistêmica (tendo como opção a injeção subcapsular de corticosteróide, feita por oftalmologista) é geralmente necessária no tratamento da uveíte posterior. Devido ao risco de seqüelas com sucessivos surtos de atividade ocular, o uso de agentes citotóxicos está indicado. Azatioprina efetivamente demonstrou melhorar o prognóstico da função ocular a longo prazo $^{(38)}$, com sua eficácia avaliada em ensaio clínico controlado. Em 48 pacientes com doença ocular por SB, houve apenas um episódio de uveíte com hipópio no grupo tratado com azatioprina contra 15 no grupo placebo, ao longo de dois anos de seguimento, havendo também redução na freqüência de úlceras orais, genitais e artrites. No mesmo estudo, em um grupo de 25 pacientes com SB sem oftalmopatia, azatioprina foi superior ao placebo na prevenção do surgimento de lesão ocular (um caso contra oito), sugerindo seu papel como fármaco de controle também das manifestações mais leves e modificadoras do curso da doença ${ }^{(39)}$. Quando reavaliados após sete anos, os pacientes do grupo tratado com azatioprina apresentaram melhor função ocular e menos complicações sistêmicas que o grupo placebo $^{(38)}$.

A superioridade da ciclosporina em relação à colchicina na prevenção de ataques oculares também foi demonstrada por BenEzra em $1988^{(40)}$. Esta última, por sua vez, não parece ser mais eficaz que placebo para este $\mathrm{fim}^{(34)}$. Ciclosporina também promoveu redução na freqüência de aftas orais e lesões cutâneas ${ }^{(40)}$. Embora não adequadamente testados, ciclofosfamida e clorambucil também são tradicionalmente considerados eficazes em reduzir a freqüência dos ataques de inflamação ocular, podendo ser empregados para este fim como segunda opção ${ }^{(1)}$.

Porém, apesar do amplo emprego de imunossupressores, o prognóstico da função ocular é ainda insatisfatório na SB, havendo risco de perda da visão útil em $30 \%$ dos pacientes masculinos e 17\% dos pacientes femininos após dez anos ${ }^{(41)}$. Quanto a reações adversas, além dos efeitos colaterais já conhecidos dos fármacos imunossupressores, na SB a ciclosporina está associada ao desenvolvimento de lesões neurológicas (demonstrados em até 30\% dos casos de SB tratados com este agente, no Japão $)^{(42)}$, ficando reservada apenas para os casos de vasculite retiniana refratária às demais drogas, em pacientes sem sinais de acometimento do SNC. Por estes motivos, novas modalidades terapêuticas que incluem agentes biológicos vem sendo avaliadas.

$\mathrm{O} \alpha$-interferon demonstrou benefício em casos de uveíte refratária ao tratamento habitual, com a vantagem particular de seu rápido início de ação (duas a quatro semanas). Os interferons (IFN) são citocinas com atividade antiviral, antitumoral e imunomoduladora que supõe-se serem eficazes no manejo da SB, basicamente, por sua ação inibidora de $\mathrm{LT} \gamma \delta+$ e estimuladora de $\mathrm{NK}^{(43)}$. Num ensaio randomizado e controlado, Alpsoy ${ }^{(44)}$ observou diminuição da dor e duração das úlceras orais, bem como na freqüência de úlceras genitais e de lesões papulopustulares $\operatorname{com} \alpha$-IFN$2 \mathrm{a}$. As demais evidências para uso de $\alpha$-IFN consistem em relatos e séries de casos. Avaliando os desfechos destes casos, Kötter ${ }^{(43)}$ sugeriu que $\alpha$-IFN pode ser indicado nas manifestações mais graves da SB (existindo mais evidências em lesões oculares) quando refratárias a pelo menos um agente imunossupressor tradicional, sendo particularmente úteis na concomitância de doença infecciosa ou maligna que contra-indique o uso de imunossupressor.

Vem sendo sugerido também o uso de agentes antiTNF em várias manifestações da $\mathrm{SB}$, porém até o momento a maioria das evidências consiste em relatos ou séries de 
casos. Sfikakis $^{(45)}$, por exemplo, relata a rápida melhora de uveíte em cinco casos, apenas 24 horas após uma infusão de infliximabe. Sucesso terapêutico com infliximabe também já foi relatado para úlceras genitais na $\mathrm{SB}^{(46)}$.

As manifestações articulares são geralmente controladas com antiinflamatórios não-hormonais (AINHs) e colchicina. Casos persistentes têm na sulfassalazina a droga de primeira escolha, podendo ser usados também azatioprina ou metotrexato $(\mathrm{MTX})^{(1)}$. Em outra linha de investigação, após a sugestão de antígenos estreptocócicos como possíveis desencadeadores da $S B$, foi demonstrada redução na freqüência de episódios de artrites e lesões mucocutâneas com o uso de penicilina benzatina, num estudo randomizado e controlado que comparou colchicina isolada contra a associação de colchicina com penicilina benzatina ${ }^{(47,48)}$.

O tratamento das lesões gastrintestinais é semelhante ao da doença inflamatória intestinal, baseado em corticosteróides sistêmicos e sulfassalazina. Se uma intervenção cirúrgica torna-se necessária (perfuração ou hemorragia gastrintestinal), corticosteróides estão indicados no pósoperatório para reduzir atividade inflamatória local e deiscências $^{(1)}$. Pulsoterapia com altas doses de corticosteróides é utilizada nas lesões intra-axiais do SNC, seguida de imunossupressores (ciclofosfamida, clorambucil, MTX ou azatioprina). As formas extra-axiais, como a trombose de seio venoso cerebral, normalmente respondem a corticosteróides sem a necessidade de imunossupressores na prevenção de recidivas $^{(24)}$. De forma semelhante são tratadas as lesões dos grandes vasos, juntamente com antiagregantes plaquetários ou anticoagulação, esta última nas tromboses ativas quando há ausência de aneurismas com risco de sangramento, que podem exigir intervenção cirúrgica, sendo a

\section{REFERÊNCIAS}

1. Sakane T, Takeno M, Suzuki N, Inaba G: Behçet's disease. N Engl J Med 21: 1284-91, 1999.

2. Yurdakul S, Hamuryudan V, Yazici H: Behçet syndrome. Curr Opin Rheumatol 16:38-42, 2004.

3. Zoubolis CC: Epidemiology of Adamantiades-Behçet's disease. Ann Med Interne (Paris) 150: 488-98, 1999.

4. Lehner T: Immunopathogenesis of Behcet's disease. Ann Med Interne (Paris) 150: 483-7, 1999.

5. International Study Group for Behçet's Disease. Criteria for diagnosis of Behçet's disease. Lancet 335: 1078-80, 1990.

6. Bhakta BB, Brennan P, James TE, Chamberlain MA, Noble BA, Silman AJ: Behçet's disease: evaluation of a new instrument to measure clinical activity. Rheumatology (Oxford) 38: 728-33, 1999. técnica endovascular recentemente utilizada com resultados favoráveis $^{(2)}$.

\section{COMENTÁRIOS}

Novos conhecimentos vêm sendo registrados no campo da SB. Na área da epidemiologia e apresentação clínica, a descrição da associação de artrites com lesões pustulares pode sugerir a existência de mecanismos etiológicos ou fisiopatogênicos comuns a estas lesões neste grupo de pacientes, com possíveis implicações em pesquisa e terapêutica, no que se refere ao papel dos antígenos estreptocócicos em desencadear períodos de atividade. No modelos fisiopatológicos, está a possibilidade de intervenção com os agentes biológicos sobre citocinas específicas neste processo que culmina com a lesão tecidual. Chegando aos ensaios clínicos, estes sugerem a indicação de terapia imunossupressora (azatioprina como primeira escolha) nos casos com comprometimento ocular definido ou em alto risco de desenvolvê-lo (homens jovens, particularmente), enquanto as manifestações mucocutâneas eventualmente podem ter controle satisfatório com colchicina nos casos mais leves (principalmente em mulheres). Porém, firmar conclusões a respeito da SB é ainda inviável devido à carência de estudos tecnicamente válidos com resultados generalizáveis. A fundamentação de instrumentos padronizados para diagnóstico e medida da atividade da síndrome pode fornecer ferramentas adequadas ao desenvolvimento de novos ensaios clínicos, tecnicamente válidos e internacionalmente reproduzíveis, que são ainda necessários tanto para fundamentar o papel de fármacos tradicionalmente indicados quanto para avaliar a eficácia dos novos agentes biológicos.
7. Ohno S, Ohguchi M, Hirose S, Matsuda H, Wakisaka A, Aizawa M: Close association of HLA-Bw51 with Behçet's disease. Arch Ophtalmol 100: 1455-8, 1982.

8. Mizuki N, Inoko H, Ohno S. Molecular Genetics (HLA) of Behçet's disease. Yonsei Med J 38: 333-49, 1997.

9. Takeno M, Kariyone A, Yamashita $\mathrm{N}$ et al: Excessive function of peripheral blood neutrophils from patient's with Behçet's disease and from HLA-B51 transgenic mice. Arthristis Rheum 38: 426-33, 1995.

10. Park SH, Park KS, Seo YI et al: Association of MICA polymorphism with HLA-B51 and disease severity in Korean patients with Behcet's disease. J Korean Med Sci 17:366-70, 2002.

11. Wallace GR, Verity DH, Delamaine LJ: MIC-A allele profiles and HLA class I associations in Behçet's disease. Immunogenetics 49:613-7, 1999.

12. Hu W, Hasan A, Wilson A et al: Experimental mucosal induction 
of uveitis with the 6- $\mathrm{kDa}$ heat shock protein-derived peptide 336-351. Eur J Immunol 28: 2444-55, 1998.

13. Lehner $\mathrm{T}$ : The role of hot shock protein, microbial and autoimmune agents in the aetiology of Behçet's disease. Int Rev Immunol 14: 21-32, 1997.

14. Krause I, Monselise Y, Milo G, Weinberger A: Anti-Saccharomyces cerevisiae antibodies-a novel serologic marker for Behcet's disease. Clin Exp Rheumatol 20(4 Suppl 26): S2 1-4, 2002.

15. Ehrlich GE: Vasculitis in Behçet's disease. Int Rev Immunol 14: 81-8, 1997.

16. Hasan A, Fortune F, Wilson A et al: Role of gamma delta T cells in pathogenesis and diagnosis of Behçet's disease. Lancet 347: 789-94, 1996

17. Kaneko F, Takahashi Y, Muramatsu R et al: Natural killer cell numbers and function in peripheral lymphoid cells in Behçet's Disease. Br J Dermatol 113: 313-8, 1985.

18. Arayssi T, Hamdan A: New insights into the pathogenesis and therapy of Behçet's Disease. Curr Opin Pharmacol 4: 183-8, 2004.

19. Espinosa G, Font J, Tassies D et al: Vascular involvement in Behçet's disease: relation with trombophilic factors, coagulation activation, and thrombomodulin. Am J Med 112: 37-43, 2002.

20. Korkmaz C, Bozan B, Kosar M, Sahin F, Gulbas Z: Is there an association of plasma homocysteine levels with vascular involvement in patients with Behçet's syndrome? Clin Exp Rheumatol 20(suppl 26): S30-S34, 2002.

21. Lee KH, Chung HS, Kim HS et al: Human alpha-enolase from endothelial cells as a target of anti-endothelial cell antibody in Behçet's disease. Arthritis Rheum 48: 2025-35, 2003.

22. Cheng TO: Some historical notes on Behçet's disease. Chest 119: 667-8, 2001.

23. Barnes CG, Yazici H: Behçet's syndrome. Rheumatology 38: 1171-6, 1999

24. Siva A, Altintas A, Saip S: Behçet's syndrome and the nervous system. Curr Opin Neurol 17: 347-57, 2004.

25. Barnes CG: Behçet's syndrome - classification criteria. Ann Med Interne (Paris) 150: 477-82, 1999.

26. Diri E, Mat C, Hamuryudan V, Yurdakul S, Hizli N, Yazici H: Papulopustular skin lesions are seen more frequeltly in patients with Behçet's syndrome who have arthritis: a controlled and masked study. Ann Rheum Dis 60: 1074-6, 2001.

27. Yazici H, Tuzun Y, Pazarli H et al: Influence of age of onset and patient's sex on the prevalence and severity of manifestations of Behcet's syndrome. Ann Rheum Dis 43: 783-9, 1984.

28. Baltaci M: A review on disease activity scores in Behçet's disease. Arthritis Res Ther 5(Suppl 2): 7, 2003.

29. Lawton G, Bhakta BB, Chamberlain MA, Tennant A: The Behcet's disease activity index. Rheumatology (Oxford) 43: 73-8, 2004.

30. Aygunduz M, Bavbek N, Ozturk M, Kaftan O, Kosar A, Kirazli $S$ : Serum beta 2 -microglobulin reflects disease activity in Behçet's disease. Rheumatol Int 22: 5-8, 2002.

31. Muftuoglu AU, Yazici H, Yurdakul S et al: Behcet's disease. Relation of serum C-reactive protein and erythrocyte sedimentation rates to disease activity. Int J Dermatol 25: 235-9, 1986.
32. Odabas AR, Karakuzu A, Cetinkaya R, Selcuk Y, Keles S, Bilen $\mathrm{H}$ : Increased serum ferritin levels in active Behçet's disease. Int J Clin Pract 56: 310-1, 2002.

33. Chang HK, Cheon KS: The clinical significance of a pathergy reaction in patients with Behçet's Disease. J Korean Med Sci 17: 371-4, 2002.

34. Saenz A, Ausejo M, Shea B, Wells G, Welch V, Tugwell P: Pharmacotherapy for Behçet's Syndrome (Cochrane Review). In: The Cochrane Library, issue 4, 2004. Oxford: Update Software.

35. Yurdakul S, Mat C, Tuzun Y et al: A double-blind trial of colchicine in Behçet's Syndrome. Arthritis Rheum 44: 2686-92, 2001.

36. Hamuryudan V, Mat C, Saip S et al: Thalidomide in the treatment of the mucocutaneous lesions of the Behçet syndrome: a randomized, double-blind, placebo-controlled trial. Ann Intern Med 128: 443-50, 1998.

37. Sharquie KE, Najim RA, Abu-Raghif AR: Dapsone in Behçet's Disease. A double-blind, placebo controlled, cross-over study. J Dermatol 29: 267-79, 2002.

38. Hamuryudan V, Özyazgan $\mathrm{Y}$, Hizli $\mathrm{N}$ et al: Azathioprine in Behçet's síndrome: effects on long term prognosis. Arthritis Rheum 40: 769-74, 1997.

39. Yazici H, Pazarli H, Barnes CG et al: A controlled trial of azathioprine in Behçet's Syndrome. N Engl J Med 322: 281-85, 1990.

40. BenEzra D, Cohen E, Chajek T, Friedman G, Pizanti S, Courten $\mathrm{C}$ et al: Evaluation of conventional therapy versus cyclosporine $\mathrm{A}$ in Behçet's Syndrome. Transplantation Proceedings 20: 136-43, 1988.

41. Tugal-Tutkun I, Onal S, Altan-Yaycioglu R, Huseyin Altunbas H, Urgancioglu M: Uveitis in Behçet Disease: an analysis of 880 patients. Am J Ophtalmol 138: 373-80, 2004.

42. Kotake S, Higashi K, Yoshikawa K, Sasamoto Y, Okamoto T, Matsuda H: Central nervous system symptoms in patients with Behçet disease receiving cyclosporine therapy. Ophtalmology 106: 586-9, 1999.

43. Kötter I, Günaydin I, Zierhut M, Stubiger N: The use of interferon-alpha in Behçet Disease: review of the literature. Semin Arthritis Rheum 33: 320-35, 2004.

44. Alpsoy E, Ourosoy C, Ylmaz E et al: Interferon alfa-2a in the treatment of Behçet Disease: a randomized, placebo controlled and double blind study. Arch Dermatol 138: 463-71, 2002.

45. Sfikakis PP, Theodossiadis PG, Katsiari GG, Kaklamanis P, Markomichelakis NN: Effect of infliximab on sight treatening panuveitis in Behçet's disease. Lancet 358: 295-6, 2001;

46. Haugeberg G, Velken M, Johnsen V: Sucessful tratment of genital ulcers with infliximab in Behçet's Disease. Ann Rheum Dis 63: 744-5, 2004.

47. Calguneri M, Ertenli I, Kiraz S, Erman M, Celik I. Effect of prophylactic benzathine penicillin on mucocutaneous symptoms of Behçet's Disease. Dermatology 192: 125-8, 1996.

48. Calgumeri M, Kiraz S, Ertenli I, Benekli M, Karaarslan Y, Celik I: The effect of prophylactic penicillin treatment on the course of arthritis episodes in patients with Behçet's Disease. A randomized clinical trial. Arthritis Rheum 39: 2062-5, 1996. 